\title{
Evaluation of Hot Workability of Powder Metallurgy Ni-Based Superalloy with Different Initial Microstructures
}

\begin{abstract}
MASAYA HIGASHI and NAOYA KANNO
The effect of the initial microstructure on the hot workability of a powder metallurgy Ni-based superalloy was investigated in the high-temperature range of $950{ }^{\circ} \mathrm{C}$ to $1180^{\circ} \mathrm{C}$ and strain rate range of 0.001 to $1.0 \mathrm{~s}^{-1}$. Six samples with different initial microstructures were fabricated by various hot isostatic pressing (HIP) conditions and subsequent treatments such as hot extrusion. The coarse-grained samples exhibited low hot workability regardless of the deformation conditions. In contrast, the hot workability of the fine-grained samples significantly varied depending on the deformation conditions. The hot workability exhibited a peak at the sub-solvus temperature of $\sim 1100{ }^{\circ} \mathrm{C}$ and decreased at temperatures higher and lower than this temperature. In addition, the hot workability decreased monotonically with increasing the strain rate. The prior particle boundaries (PPBs) acted as cavity nucleation sites and crack paths, especially at lower temperatures and higher strain rates, resulting in early fracture and low hot workability. With decreasing the grain size, the hot workability at the peak temperature improved. The extruded sample with the smallest grain size exhibited the best hot workability, owing to the avoidance of PPB fracture and the acceleration of dynamic recrystallization.
\end{abstract}

https://doi.org/10.1007/s11661-020-06085-5

(C) The Author(s) 2020

\section{INTRODUCTION}

TURBINE disks are one of the aero-engine components exposed to extreme environments, and polycrystalline Ni-based superalloys that exhibit balanced mechanical properties, such as high creep resistance, high tensile strength, and low cycle fatigue at temperatures of $700{ }^{\circ} \mathrm{C}$ and higher are commonly used to produce these disks. Conventionally, the superalloys used for turbine disks have been processed by the cast and wrought $(\mathrm{C} \& \mathrm{~W})$ route. ${ }^{[1]}$ With an increase in the demand for higher-temperature resistant alloys for aero-engines, higher-strength disk superalloys have been developed by increasing alloying element concentrations and $\gamma^{\prime}$ volume fractions. ${ }^{[2,3]}$ In order to form such high-strength superalloys into complex shapes, it is necessary to improve the processing technique as well as the alloy development toward the practical application. The powder metallurgy $(\mathrm{P} / \mathrm{M})$ route allows for the formation of fine microstructure which helps to improve hot workability of such high-strength superalloys. The

MASAYA HIGASHI and NAOYA KANNO are with the Technology \& Intelligence Integration, IHI Corporation, 1 Shinnakahara-cho, Isogo-ku, Yokohama 235-8501, Japan. Contact e-mail: higashi1032@ihi-g.com

Manuscript submitted July 22, 2020; accepted October 24, 2020.

Article published online November 17, 2020 conventional $\mathrm{P} / \mathrm{M}$ processing route consists of the powder consolidation by hot isostatic pressing (HIP), and subsequent hot extrusion followed by isothermal forging. ${ }^{[4]}$ In the case of conventional $\mathrm{C} \& \mathrm{~W}$ route, a hot forging is usually performed as the final forging process, instead of an isothermal forging, suggesting that a certain degree of heat loss is acceptable. In contrast, $\mathrm{P} /$ $\mathrm{M}$ superalloys are usually isothermally forged using a die heated to temperatures higher than $1000{ }^{\circ} \mathrm{C}$ at a low strain rate, suggesting that the processing window for high-strength $\mathrm{P} / \mathrm{M}$ superalloys is strictly limited because of the low hot workability.

It is important to select the appropriate deformation conditions to obtain the desired level of hot workability. The hot deformation behaviors of superalloys have been investigated extensively through isothermal compression tests in both $\mathrm{C} \& \mathrm{~W}$ and $\mathrm{P} / \mathrm{M}$ superalloys. The deformation conditions, such as the temperature and strain rate, have a significant effect on the flow behavior and microstructural evolution, which are largely dominated by dynamic recrystallization (DRX).$^{[5-8]}$ Further, based on the obtained results, the processing conditions for various superalloys have been optimized. However, most of these studies were performed using samples with the same initial microstructure, and there have been little studies on the effect of the initial microstructure of $\mathrm{P} / \mathrm{M}$ superalloys on the hot workability. Isothermal forging utilizes the superplasticity of superalloys. For superplastic deformation to occur, the microstructure 
should be sufficiently fine, and the deformation conditions should be appropriate (low strain rate and high temperature). ${ }^{[9]}$ Therefore, it is important to understand the effects of the deformation condition and initial microstructure on the hot workability to promote the superplastic deformation for the successful isothermal forging.

In the case of $\mathrm{P} / \mathrm{M}$ superalloys, there is a concern of the prior particle boundaries (PPBs) which are decorated by brittle precipitates such as oxide and carbide. ${ }^{[10-18]}$ It has been found that the PPBs have an adverse effect on the mechanical properties because they tend to act as crack initiation sites and paths. To overcome the PPB-related problem, it is necessary to first clarify how the presence of PPBs in the as-HIP superalloys affects their hot workability, as the effect of PPBs on the hot workability is not yet well understood owing to the difficulty in evaluating it quantitatively through compression tests. Only recently, we have elucidated the effect of PPB density on the hot workability using the powders with different particle sizes through high-temperature tensile tests. ${ }^{[18]}$ Using the coarse powder particles was found to be effective to decrease the PPB density of the as-HIP sample and improve the hot workability. Within that study, HIP condition was fixed at a $\gamma^{\prime}$ sub-solvus temperature of $1120{ }^{\circ} \mathrm{C}$, pressure of $98 \mathrm{MPa}$ and holding time of 4 hours. Therefore, all samples exhibited similar average grain sizes of $\sim 8 \mu \mathrm{m}$.

In this study, the initial powder particle size range was fixed. Instead, various microstructures with different grain sizes and $\gamma^{\prime}$ morphologies were obtained by changing the HIP conditions and subsequent treatments after HIP. Then, the effect of initial microstructure on the hot workability was investigated with the aim of optimizing the initial microstructure before isothermal forging. At the same time, one of the HIP samples was followed by hot extrusion to understand the effect of the hot extrusion. Based on the obtained results, appropriate deformation condition and initial microstructure of powder metallurgy Ni-based superalloy are proposed to improve the hot workability. This study would be fundamental guidance for successful hot workings of $\mathrm{P} / \mathrm{M}$ superalloys such as extrusion and isothermal forging.

\section{EXPERIMENTAL}

A representative high-strength disk superalloy (alloy $720 \mathrm{Li}$ ) was used in this study. The initial powder was fabricated by gas atomization, and powder with particle sizes of $<106 \mu \mathrm{m}$ was used with references to some studies. ${ }^{[4,15]}$ The $\mathrm{D}_{10}, \mathrm{D}_{50}$, and $\mathrm{D}_{90}$ values of the powder were $10.8,36.8$, and $78.4 \mu \mathrm{m}$, respectively. The nominal chemical composition of the powder is given in Table I.

The powder was filled into the stainless-steel container, and sealed by electron beam in vacuum followed by HIP consolidation, and HIP billets with the diameter of $\sim 100 \mathrm{~mm}$ and height of $\sim 100 \mathrm{~mm}$ were obtained. Various HIP conditions and subsequent treatments are shown in Table II. The $\gamma^{\prime}$ solvus temperature of this alloy was determined to be $\sim 1150{ }^{\circ} \mathrm{C}$. A $\gamma^{\prime}$ sub-solvus HIP temperature of $1120{ }^{\circ} \mathrm{C}$ was selected based on the solvus temperature (sample A). Further, the HIP conditions such as the HIP pressure, holding time, and temperature were varied (samples B, C, and D, respectively). Moreover, a super-solvus heat treatment was performed at $1190{ }^{\circ} \mathrm{C}$ for 1 hour to homogenize the as-HIP microstructure (sample E). In addition, an as-HIP sample fabricated under the same HIP condition as sample $\mathrm{A}$ was followed by hot extrusion at $1100{ }^{\circ} \mathrm{C}$ (sample F). All the samples were fabricated using the same batch of gas-atomized powder.

Tensile test specimens with a gauge length of $15 \mathrm{~mm}$ and diameter of $6 \mathrm{~mm}$ were fabricated from the various samples. The specimens of the extruded sample were extracted in parallel to the extrusion direction. The tensile tests were performed using a Thermecmaster-Z machine over a wide temperature range $\left(950{ }^{\circ} \mathrm{C}\right.$ to 1180 ${ }^{\circ} \mathrm{C}$ ) and a strain rate of $0.001 \mathrm{~s}^{-1}$ in vacuum. Further, the strain rate was varied from 0.001 to $1.0 \mathrm{~s}^{-1}$ for some of the samples (A, D, and F) at $1050{ }^{\circ} \mathrm{C}$. The tensile specimens were induction heated to the deformation temperature and held at the temperature for 5 minutes before the tests. The tests were continued until fracture, which was followed by gas quenching to maintain the hot deformation microstructure. The hot workability was evaluated based on the reduction of area (RA) values. $^{[14,15,18,19]}$

The initial and fracture microstructures of the samples were characterized using optical microscopy (OM, Leica DM2500 M), scanning electron microscopy (SEM, JSM 7100F and SU5000), and electron backscatter diffraction (EBSD) analysis. The EBSD data were analyzed by an OIM analysis ver.7.3.1. The samples used for the microstructural observations were prepared by the standard metallographic method and subjected to a final polish using a $0.04 \mu \mathrm{m}$ colloidal silica suspension. Some as-HIP samples were electrolytically etched to observe $\gamma^{\prime}$ precipitates more clearly.

\section{RESULTS}

\section{A. Initial Microstructures}

1. Prior particle boundaries (PPBS) and $\gamma^{\prime}$ precipitates SEM backscattered electron (BSE) images of the initial microstructures showing the PPB precipitates and $\gamma^{\prime}$ precipitate morphologies are given in Figure 1. Spherical PPBs decorated by dark precipitates were observed in all the as-HIP samples, as indicated by the blue dotted line (Figures 1(a) through (e)). These microstructures suggest that the formation of PPB precipitate networks was unavoidable under the selected HIP conditions. Most of the PPB precipitates were formed along the grain boundary. In contrast, it can be confirmed that PPB precipitate networks were heavily distorted by the hot extrusion along the extrusion direction, and the PPB precipitates were no longer at the grain boundaries but within grains (Figure 1(f)).

The $\gamma^{\prime}$ precipitates of the as-HIP samples had the inhomogeneous morphologies. Two types of $\gamma^{\prime}$ phase 
Table I. Nominal Chemical Composition of Powders Used in this Study (Wt Pct)

\begin{tabular}{lcccccccccc}
\hline Ni & Fe & Cr & Co & Mo & W & Al & Ti & B & C & Zr \\
\hline Bal. & 0.06 & 16 & 15 & 3 & 1.25 & 2.5 & 5 & 0.018 & 0.025 & 0.030 \\
\hline
\end{tabular}

Table II. Various P/M Superalloy Samples Fabricated Using Different HIP Conditions and Subsequent Treatments

\begin{tabular}{lcccl}
\hline & \multicolumn{3}{c}{ HIP Condition } & \\
\cline { 2 - 4 } Sample & Temperature $\left({ }^{\circ} \mathrm{C}\right)$ & Pressure $(\mathrm{MPa})$ & Holding Time $(\mathrm{h})$ & Following Treatment \\
\hline A & 1120 & 98 & 4 & - \\
$\mathrm{B}$ & 1120 & 196 & 4 & - \\
$\mathrm{C}$ & 1120 & 98 & 24 & - \\
$\mathrm{D}$ & 1170 & 98 & 4 & heat treatment at $1190^{\circ} \mathrm{C}$ for $1 \mathrm{~h}(\mathrm{air}$ cooling) \\
$\mathrm{E}$ & 1120 & 98 & 4 & extrusion at $1100^{\circ} \mathrm{C}$ \\
F & 1120 & 98 & 4 & \\
\hline
\end{tabular}

did precipitate in the sample $\mathrm{A}$; coarse and irregular-shaped $\gamma^{\prime}$ precipitates at the grain boundaries, and fine and cuboidal precipitates within grains (Figure 1(a)). The coarse $\gamma^{\prime}$ precipitates seemed to get slightly refined by the increase in the HIP pressure (Figure 1(b)). In contrast, the morphology of the $\gamma^{\prime}$ precipitates varied in the samples $\mathrm{C}-\mathrm{F}$. During long HIP holding time (sample $\mathrm{C}$ ), the morphology got further inhomogeneous and had the irregular shapes (Figure 1(c)). When the HIP treatment was performed above the $\gamma^{\prime}$ solvus temperature (sample D), both flower-like and needle-like $\gamma^{\prime}$ precipitates were formed; these $\gamma^{\prime}$ precipitate morphologies are typical to HIP samples performed at a $\gamma^{\prime}$ super-solvus temperature (Figure 1(d)). ${ }^{[12,14,15]}$ After the super-solvus heat treatment at $1190{ }^{\circ} \mathrm{C}$ for 1 hour (sample E), $\gamma^{\prime}$ precipitates were fully solutionized within the matrix $\gamma$ phase, resulting in significant grain growth (Figure 1(e)). Very fine cooling $\gamma^{\prime}$ precipitates with the sizes of $\sim 100 \mathrm{~nm}$ were formed owing to the air cooling, as shown in the magnified image inset in Figure 1(e). Finally, for the extruded sample $\mathrm{F}$, a bimodal $\gamma^{\prime}$ precipitate microstructure was observed which is typical to that after hot workings (Figure 1(f)). ${ }^{[1]}$ It consisted of the equiaxed primary $\gamma^{\prime}$ precipitates and fine cooling $\gamma^{\prime}$ precipitates with sizes of $\sim 1 \mu \mathrm{m}$ and $\sim 100 \mathrm{~nm}$, respectively, as shown in the inset of Figure 1(f). Thus, there were significant differences in the $\gamma^{\prime}$ precipitate morphologies and PPB networks of the samples fabricated under different conditions.

\section{Grain microstructure}

Inverse pole figure (IPF) maps showing the grain microstructures are given in Figure 2. The measured average grain sizes are given in the maps. At the sub-solvus HIP temperature of $1120^{\circ} \mathrm{C}$ (samples A-C), the microstructure consisted of fine equiaxed grains (Figure 2(a) through (c)). The average grain sizes were 6.8 (sample A), 6.5 (sample B), and 8.2 (sample C).
These results indicate that the HIP pressure has little effect on the grain size when it lies between 98 and 196 $\mathrm{MPa}$, but the long holding time leads to a slight grain growth between 4 and 24 hours. In contrast, the super-solvus HIP treatment at $1170{ }^{\circ} \mathrm{C}$ (sample D) resulted in significant grain coarsening up to $19.0 \mu \mathrm{m}$ because of the dissolution of $\gamma^{\prime}$ precipitates, which pin the grain growth (Figure 2(d)). In addition, this sample exhibited serrated grain boundaries. It is well known that grain boundary serration is attributable to slow cooling from the super-solvus temperature. ${ }^{[12]}$ After the super-solvus heat treatment at $1190{ }^{\circ} \mathrm{C}$ for 1 hour (sample E), a large number of spherical coarse grains formed, indicating that grain growth are strongly pinned by PPB precipitates. The average grain size further increased to $20.0 \mu \mathrm{m}$ (Figure 2(e)). However, apparent grain boundary serration was not found because of air cooling. A uniform fine microstructure was formed after extrusion at $1100{ }^{\circ} \mathrm{C}$ (Figure 2(f)), owing to the DRX occurrence. The grain size of the extruded sample $\mathrm{F}$ decreased to $3.7 \mu \mathrm{m}$ approximately half of that of the as-HIP sample A $(6.8 \mu \mathrm{m})$.

\section{B. Flow Behavior During High-Temperature Tensile Tests}

Figure 3(a) through (c) shows the representative true stress-strain curves deformed at a strain rate of 0.001 $\mathrm{s}^{-1}$ and different temperatures $\left(950{ }^{\circ} \mathrm{C}, 1100{ }^{\circ} \mathrm{C}\right.$, and $1180{ }^{\circ} \mathrm{C}$, respectively). For most of the samples, the flow stress increased rapidly to the peak value with the increase in the strain. This was followed by slow flow softening. This flow behavior with a single peak is DRX dominated type, which is typical to various materials with low stacking fault energies. ${ }^{[5-8]}$ The peak stress corresponds to the onset of DRX. Figure 4 shows the peak flow stress at a strain rate of $0.001 \mathrm{~s}^{-1}$ and different temperatures for the various samples as a function of the initial average grain size. Obviously, there were 

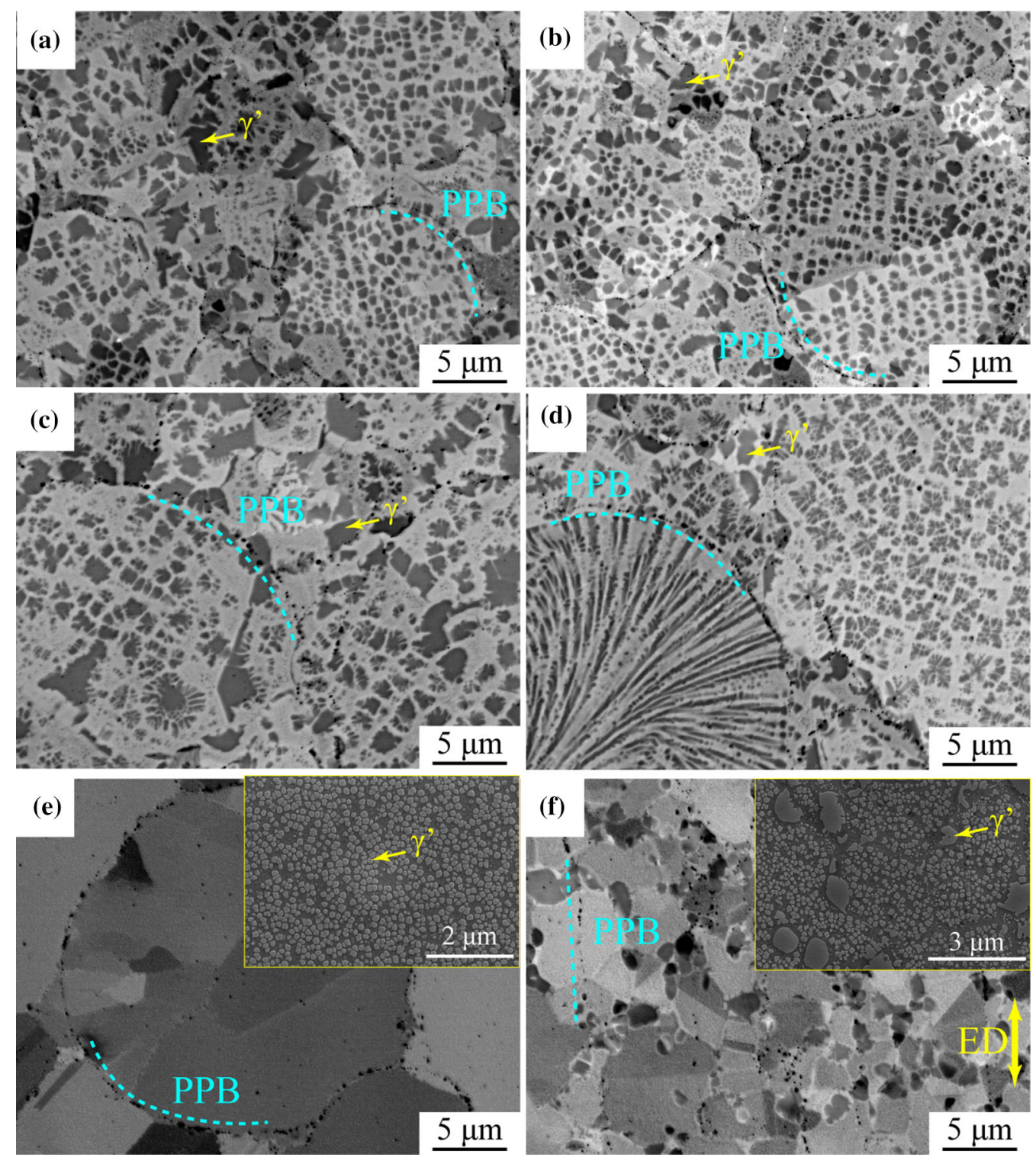

Fig. 1-SEM-BSE images showing PPB precipitate networks and $\gamma^{\prime}$ precipitates in various samples: $(a)$ sample A, $(b)$ sample B, $(c)$ sample C, $(d)$ sample D, (e) sample E, and $(f)$ sample F. Insets in (e) and (f) show SEM secondary electron images of $\gamma^{\prime}$ precipitates. The $\gamma^{\prime}$ precipitate is indicated by yellow arrow and representative PPB is partially indicated by blue dotted line. (ED: extrusion direction) (Color figure online).

significant differences in flow behaviors depending on the deformation temperature. The flow stress decreased with the increase in the temperature, which was true for all samples (Figures 3 and 4). The initial microstructure also had a significant effect on the flow behavior at all deformation temperatures. It should be noted the peak stress decreased with the decrease in the grain size for all temperatures. At a super-solvus deformation temperature of $1180{ }^{\circ} \mathrm{C}$ (Figures 3(c) and 4), coarse-grained samples (D and E) exhibited $\sim 30$ pct higher peak stress comparing with fine-grained samples (A, B, and $\mathrm{F}$ ). Then, the effect of grain size on the flow stress became more apparent with decreasing the deformation temperature (Figures 3(a), (b) and 4).

The differences in the peak flow stresses among samples were similar to those in their yield strengths, meaning that the samples with a high yield strength necessarily showed a high peak stress as well (Figures 3 and 4). It is obvious that this tendency does not follow the conventional Hall-Petch relationship, which states that the yield strength of polycrystalline materials increases as the grain size decreases. ${ }^{[20]}$ The inverse Hall-Petch relationship observed in this study suggests that the deformation mode at the hot working temperatures is superplastic deformation which is dominated by grain boundary sliding. ${ }^{[21]}$ This tendency can be confirmed from a decrease in the flow stress with decreasing the grain size, which was true even at a lowest deformation temperature of $950{ }^{\circ} \mathrm{C}$ (Figures 3(a) and 4).

The strain rate dependence on the flow behavior for the samples $\mathrm{A}$ and $\mathrm{F}$ deformed at $1050{ }^{\circ} \mathrm{C}$ is shown in Figure 3(d). Even at the higher strain rates $(0.01$ and 0.1 $\mathrm{s}^{-1}$ ), sample $\mathrm{F}$ with finer grain size exhibited a lower 

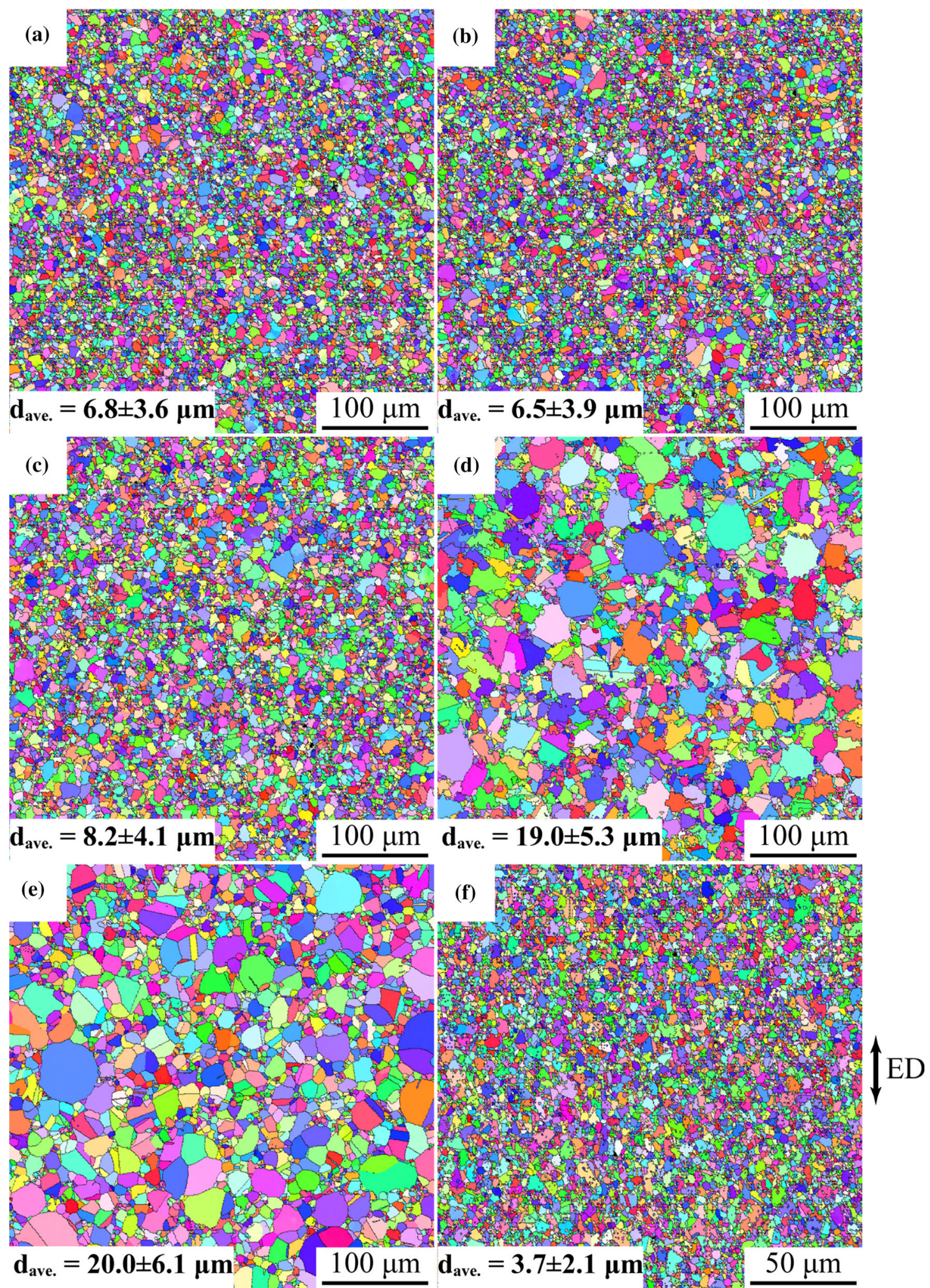

Fig. 2-EBSD-IPF maps of various samples showing initial grain microstructures: $(a)$ sample A, (b) sample B, $(c)$ sample C, $(d)$ sample D, (e) sample E, and $(f)$ sample F. Measured average grain size and its deviation of each sample is given in top right of corresponding map.

flow stress than that of sample A, although this difference became negligible at the highest strain rate of $1.0 \mathrm{~s}^{-1}$. The strain rate sensitivity parameter, $m$, which is often used to describe the superplasticity, can be obtained using the following expression: $m=\delta \ln \sigma / \delta$ $\ln \varepsilon .^{[9]}$ The higher the $m$ value, the more likely it is that 


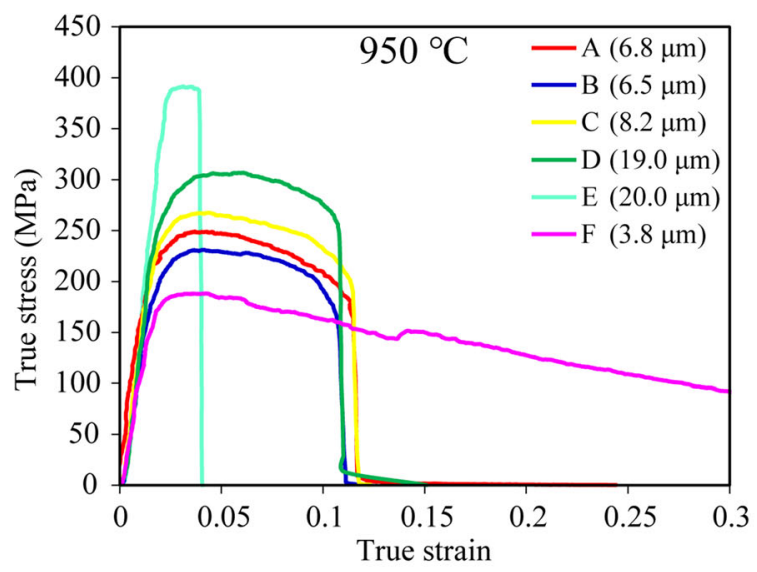

(a)

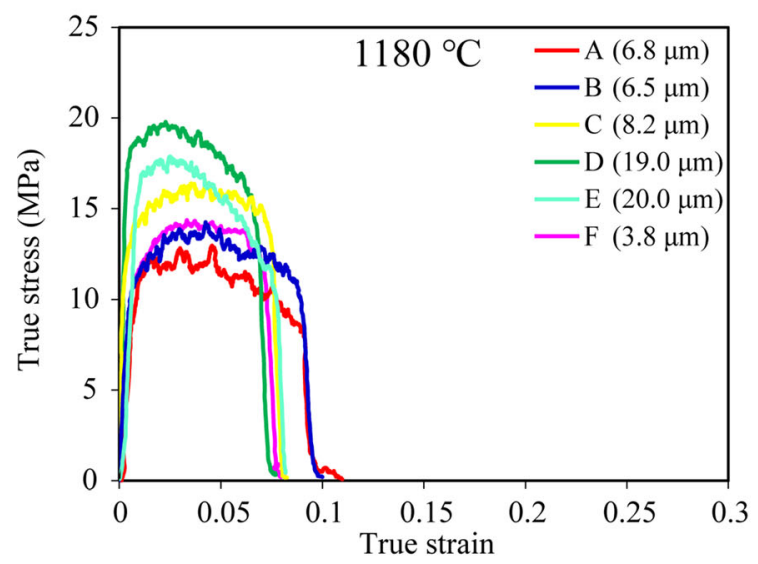

(c)

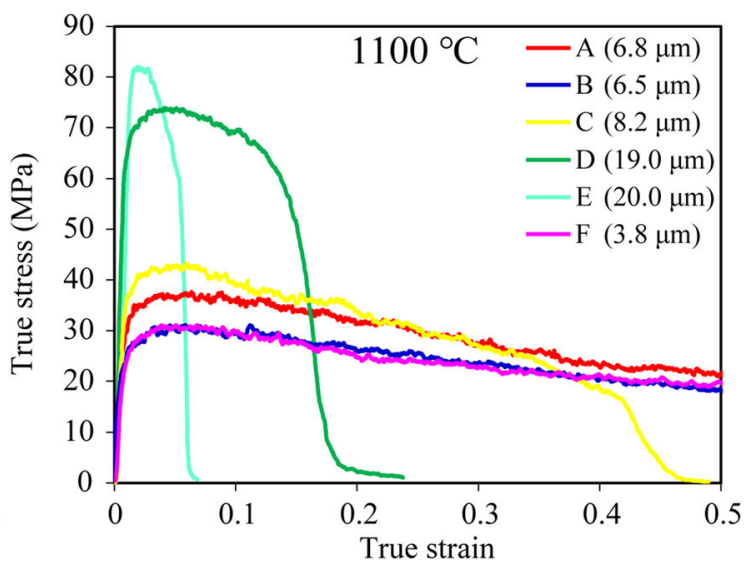

(b)

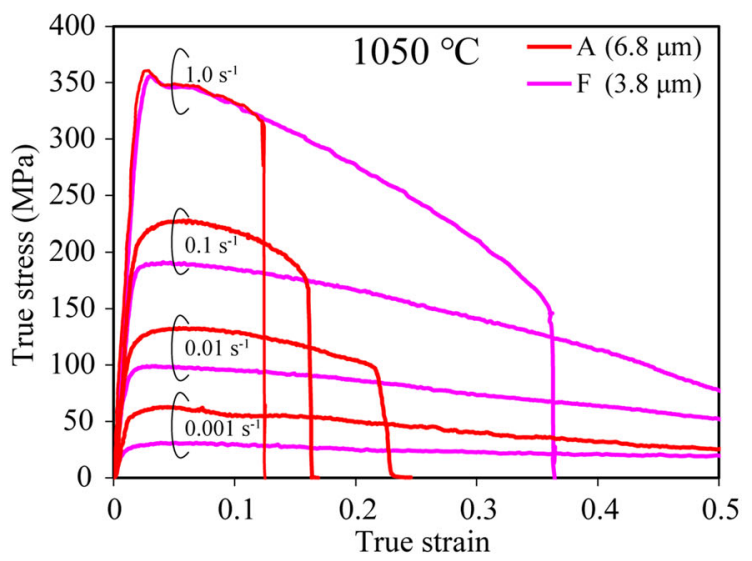

(d)

Fig. 3-Typical true stress-strain curves of various samples at strain rate of $0.001 \mathrm{~s}^{-1}$ with different temperatures $(a) 950,(b) 1100$, and $(c) 1180$ $\left.{ }^{\circ} \mathrm{C}\right)$. (d) Strain rate dependence on the stress-strain curves of samples A and F deformed at $1050{ }^{\circ} \mathrm{C}$ from 0.001 to $1.0 \mathrm{~s}^{-1}$.

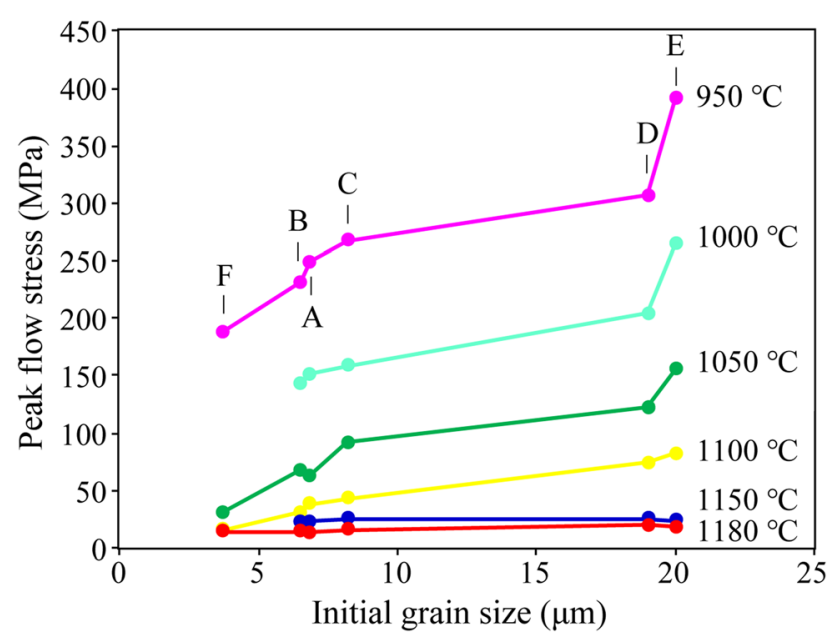

Fig. 4 - Peak flow stress as a function of initial grain size at 0.001 $\mathrm{s}^{-1}$ with different temperatures. superplastic deformation occurs. The initial grain size and strain rate sensitivity parameter $(m)$ values for the samples A, D, and $\mathrm{F}$ at $1050{ }^{\circ} \mathrm{C}$ are listed in Table III. The $m$ value increased with decreasing the grain size. The maximum $m$ value was 0.35 for the extruded sample F with average grain size of $3.7 \mu \mathrm{m}$. Further, the $m$ value of the sample A was 0.25 and lower than that of the sample $\mathrm{F}$ but closer to the desired value of 0.3 . Finally, the $m$ value of sample $\mathrm{D}$, which had a coarse-grained microstructure, was significantly low (0.15).

Comparing with the flow curves of the two samples (Figure 3(d)), slow flow hardening occurred after the yield stress till the peak flow stress in the sample A. In contrast, this type of flow hardening was not almost observed in the case of the extruded sample $F$, and the flow stress immediately reached a peak after the yield stress and gradual flow softening started. This tendency is apparent especially at the strain rates of 0.01 and 0.1 $\mathrm{s}^{-1}$. This flow behavior difference indicates that DRX started at a low stress (strain) in the case of extruded 
sample $\mathrm{F}$ as compared with that for the as-HIP sample A. Such difference in flow behavior depending on the grain size was also true at deformation temperatures of $950{ }^{\circ} \mathrm{C}$ and $1100{ }^{\circ} \mathrm{C}$.

\section{Evaluation of Hot Workability}

\section{Temperature dependence}

Figure 5(a) shows RA values for the various samples as a function of the deformation temperature at a strain rate of $0.001 \mathrm{~s}^{-1}$. It is apparent that the hot workability is significantly affected by both the deformation temperature and initial microstructure. At a lowest temperature $\left(950{ }^{\circ} \mathrm{C}\right)$, all the samples except for the extruded sample F showed RA values lower than 20 pct. With the increase in the deformation temperature, the RA values varied significantly depending on the initial microstructure. Samples D and E with coarse-grained microstructures continued to exhibit low RA values of less than 30 pct for all temperatures up to super-solvus temperature of $1180{ }^{\circ} \mathrm{C}$. In contrast, in the case of the samples A, B, $\mathrm{C}$, and $\mathrm{F}$ with fine-grained microstructures, the RA values gradually increased with increasing the deformation temperature and exhibited a sharp peak at approximately $1050{ }^{\circ} \mathrm{C}$ to $1100{ }^{\circ} \mathrm{C}$. Then, as the deformation temperature was increased further $\left(\geq \gamma^{\prime}\right.$ solvus temperature of $1150{ }^{\circ} \mathrm{C}$ ), the RA value decreased again and became less than 20 pct at $1180{ }^{\circ} \mathrm{C}$ in all samples. To summarize, the hot workability is so sensitive to the initial microstructure, especially at intermediate temperatures $\left(1050{ }^{\circ} \mathrm{C}\right.$ and $\left.1100{ }^{\circ} \mathrm{C}\right)$. In contrast, there is little

Table III. Relationship Between Initial Grain Size and $\boldsymbol{m}$ Value (Strain Rate Sensitivity) Calculated Using Peak Flow Stress for Strain Rates from 0.001 to $1.0 \mathrm{~s}^{-1}$ at the Deformation Temperature of $1050{ }^{\circ} \mathrm{C}$

\begin{tabular}{llcl}
\hline Sample & A & D & F \\
\hline Initial Grain Size & 6.8 & 19.0 & 3.7 \\
Strain Rate Sensitivity $m$ & 0.25 & 0.15 & 0.35 \\
\hline
\end{tabular}

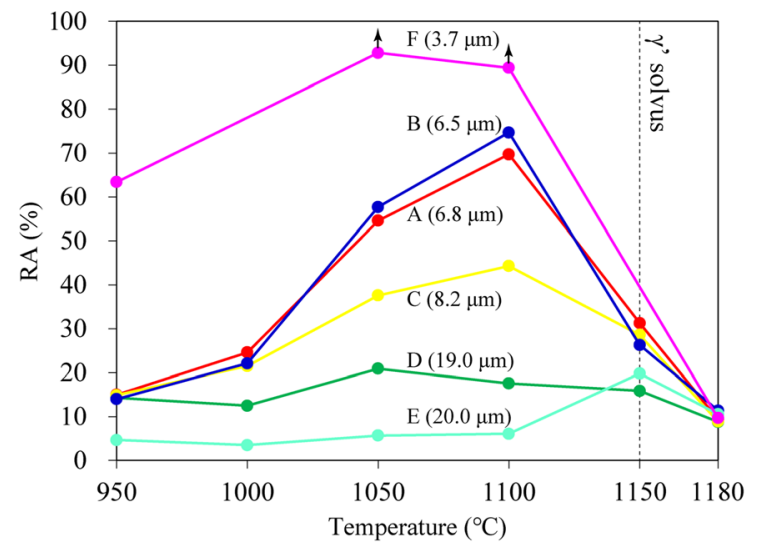

(a) effect of the initial microstructure at higher $\left(1150^{\circ} \mathrm{C}\right.$ and $1180{ }^{\circ} \mathrm{C}$ ) and lower temperatures $\left(950^{\circ} \mathrm{C}\right.$ and $\left.1000^{\circ} \mathrm{C}\right)$. Notably, the RA values increased with a decrease in the grain size at the optimal deformation temperatures $\left(1050{ }^{\circ} \mathrm{C}\right.$ and $\left.1100{ }^{\circ} \mathrm{C}\right)$. The extruded sample $\mathrm{F}$ exhibited the highest RA value of $\sim 90$ pct at the peak temperatures of $1050{ }^{\circ} \mathrm{C}$ and $1100{ }^{\circ} \mathrm{C}$. Sample E with the largest grain size showed the lowest RA value (less than 10 pct) even at the intermediate temperature. The fracture elongations are shown in Figure 5(b). The dependence of the fracture elongation on the temperature and initial microstructure was consistent with those of the RA values (Figure 5(a)). The sample $\mathrm{F}$ deformed at the temperatures of $1050{ }^{\circ} \mathrm{C}$ and $1100{ }^{\circ} \mathrm{C}$ exhibited elongations greater than 300 pct. In fact, the deformation temperatures of these tensile specimens decreased unexpectedly owing to the specimen deviation from the induction heating zone because of the large elongations. Therefore, the RA values and elongations of these samples would be even higher if the temperature were kept constant during the deformation process. These samples are indicated by black arrows. The most notable difference between the as-HIP samples and the extruded one was in the hot workabilities at a low temperature $\left(950{ }^{\circ} \mathrm{C}\right)$. Although the RA values of the as-HIP samples decreased sharply at $950{ }^{\circ} \mathrm{C}$ compared to those at the peak temperature $\left(1100^{\circ} \mathrm{C}\right)$, the extruded sample exhibited a high RA value of $\sim 60$ pct.

\section{Strain rate dependence}

Figure 6 shows the strain rate dependence of the RA values at $1050{ }^{\circ} \mathrm{C}$ for samples with completely different microstructures (samples A, D, and F). The effect of the strain rate on the hot workability varied with the initial microstructure. There was almost no effect of the strain rate on the $\mathrm{RA}$ value in the sample $\mathrm{D}$ with a coarse-grained microstructure, and the RA value remained as low as 20 pct at all strain rates. In contrast, a significant dependence on the strain rate was observed for samples $\mathrm{A}$ and $\mathrm{F}$ with fine microstructures. Their RA values decreased with the increase in the strain rate. The high RA value of 54.6 pct at a strain rate of 0.001 $\mathrm{s}^{-1}$ decreased suddenly to $22.8 \mathrm{pct}$ at $0.01 \mathrm{~s}^{-1}$ in the

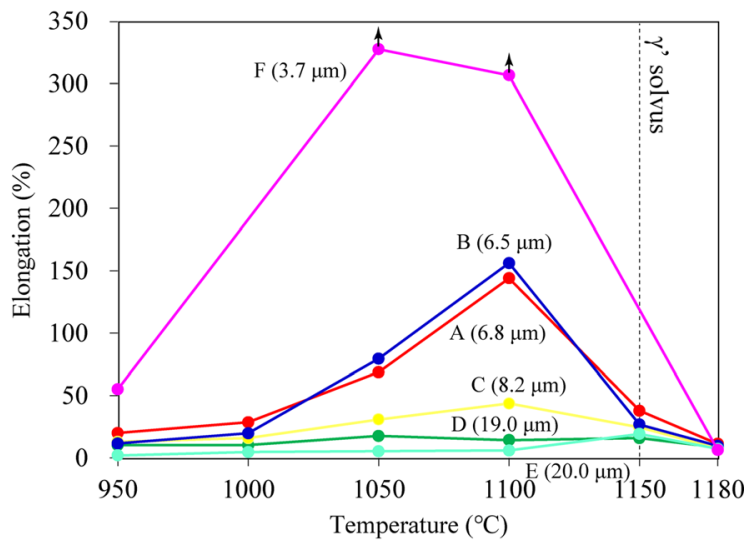

(b)

Fig. 5-(a) Reduction of area (RA) values and (b) fracture elongations as a function of deformation temperature at the strain rate of $0.001 \mathrm{~s}^{-1}$. 


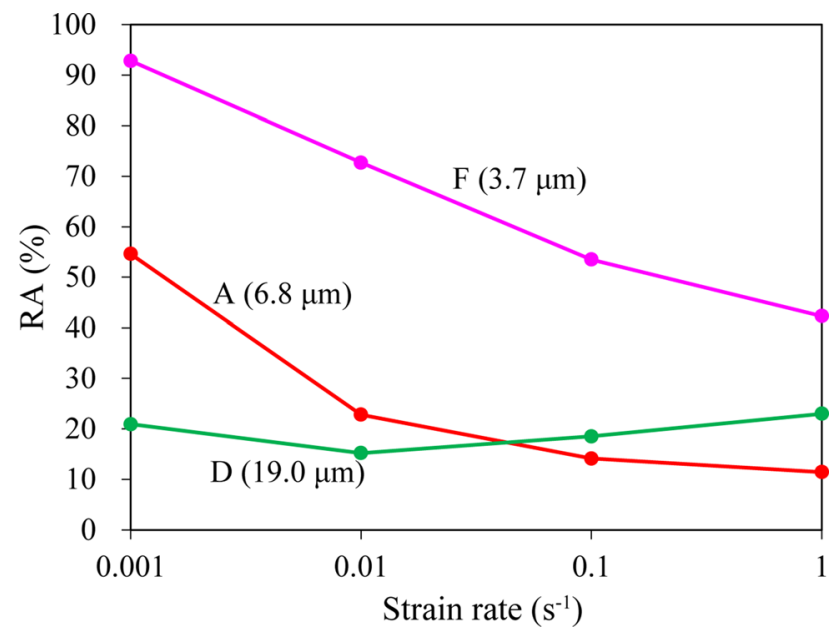

Fig. 6- RA values as a function of strain rate for samples A, D, and $\mathrm{F}$ deformed at $1050{ }^{\circ} \mathrm{C}$ for strain rates from 0.001 to $1.0 \mathrm{~s}^{-1}$.

sample A. Further, the RA value continued to decrease with increasing the strain rate. The strain rate dependence of sample $\mathrm{F}$ was such that its RA value decreased almost linearly with increasing the strain rate. Even at the highest strain rate of $1.0 \mathrm{~s}^{-1}$, the RA value was 42.3 pct and higher than that of sample $A$ at $0.01 \mathrm{~s}^{-1}$ and that of sample $\mathrm{F}$ at $0.001 \mathrm{~s}^{-1}$.

\section{Effect of Deformation Condition and Initial Microstructure on Fracture Characteristics}

\section{High temperature}

EBSD image quality (IQ) + IPF maps and SEM-BSE images of cross sections of the samples $\mathrm{A}$ and $\mathrm{F}$ near the fracture tips deformed at $1180{ }^{\circ} \mathrm{C}$ are shown in Figure 7. It can be seen that a large number of intergranular cracks propagated perpendicular to the tensile direction in both samples. In addition, the average grain sizes of the two samples after deformation were 19.4 (sample A) and $16.2 \mu \mathrm{m}$ (sample $\mathrm{F}$ ), respectively, indicating the occurrence of the significant grain coarsening due to the super-solvus deformation temperature of $1180^{\circ} \mathrm{C}$. In the sample A, spherical coarse grains pinned by PPBs were frequently observed (Figures 7(a) and (c)). Cracks often propagated around such coarse grains vertically to the tensile direction. This indicates that the PPBs acted as crack paths in the sample A. On the other hand, such apparent PPB crack was not found in the sample F because of the heavily distorted PPBs by extrusion (Figures 7(b) and (d)). In addition, it can be confirmed that grain growth behavior at the super-solvus temperature is different between the two samples. SEM-BSE images reveal that grain growth is strongly pinned by PPB precipitates in the sample A (Figure 7(c)), which indicates that grain size within PPB is largely determined by the powder particle size. In this study, the powder with a wide particle size range $<106 \mu \mathrm{m}$ was used, which resulted in inhomogeneous grain growth of the as-HIP sample. On the other hand, microstructures were refined by DRX, and PPB precipitates were no longer at the grain boundary but within grains in the extruded sample
(Figure 7(d)). Therefore, pinning effect of PPB precipitates should be weak in the early grain growth stage until the grains reach the PPB precipitate rows. These are the reason for the homogeneous grain growth of sample F. Although grain growth behavior is slightly different depending on the samples, only 5-minute holding at the super-solvus temperature $\left(1180{ }^{\circ} \mathrm{C}\right)$ before deformation was sufficient for significant grain growth to occur. This result is consistent with the study on microstructure evolution of a $\mathrm{P} / \mathrm{M}$ low-solvus, high-refractory superalloy. ${ }^{[8,22,23]}$

\section{Low temperature}

The fracture characteristics at a lower temperature $\left(950^{\circ} \mathrm{C}\right)$ are shown in Figure 8. A large number of long curved cracks along the PPBs were observed in the sample A (Figures 8(a) and (c)). Furthermore, fine cavities were also formed along PPBs. In contrast, the extruded sample $\mathrm{F}$ exhibited a completely different fracture microstructure. Visible cracks along PPBs were not found. Instead, a large number of cavities aligned parallel to the tensile direction were observed (Figures 8(b) and (d)). These cavities are typical defects formed during superplastic deformation. ${ }^{[24-26]}$ The microstructural evolution during hot deformation was also largely different between the two samples. The average grain size in the sample A after deformation was almost the same with that of before deformation (Figures 2(a) and 8(c)). On the other hand, in the case of the extruded sample $\mathrm{F}$, it was further refined from 3.7 $\mu \mathrm{m}$ (Figure 2(f)) to $2.7 \mu \mathrm{m}$ (Figure $8(\mathrm{~d})$ ), indicating the frequent occurrence of DRX during the large deformation (Figure 3(a)).

\section{Peak temperature for different strain rates}

The fracture characteristics of samples $\mathrm{A}$ and $\mathrm{F}$ at the peak temperature of $1050{ }^{\circ} \mathrm{C}$ with different strain rates are shown in Figure 9. In the sample A, the PPB cracks observed at the lower temperature of $950{ }^{\circ} \mathrm{C}$ (Figure 8) were not found at the lowest strain rate of $0.001 \mathrm{~s}^{-1}$. Instead, a large number of coarse triangular cavities nucleated at the PPBs, as indicated by the red arrows (Figure 9(a)). Subsequently, with the increase in the strain rate, these triangular cavities at the PPBs decreased, and distinct PPB cracks were formed (Figures 9(b) and (c)). Almost complete PPB fracture occurred at a strain rate of $0.1 \mathrm{~s}^{-1}$, as was also the case at $950{ }^{\circ} \mathrm{C}$ (Figure 8(a)). Thus, the fracture characteristics varied with increasing the strain rate in the HIP sample $\mathrm{A}$ at $1050{ }^{\circ} \mathrm{C}$. It can be assumed that the occurrence of the apparent PPB fracture at $0.01 \mathrm{~s}^{-1}$ resulted in a sudden decrease in the hot workability compared at $0.001 \mathrm{~s}^{-1}$ (Figure 6). In contrast, visible PPB cracks were not observed even at the highest strain rate of $1.0 \mathrm{~s}^{-1}$ in the extruded sample $\mathrm{F}$ (Figure 9(d) through (f)). Instead, numerous cavities aligned parallel to the tensile direction were seen at all the strain rates, indicating the occurrence of superplastic deformation. The number of cavities increased, and the cavities became fine with increasing the strain rate. The cracks propagating vertically to the tensile direction were 

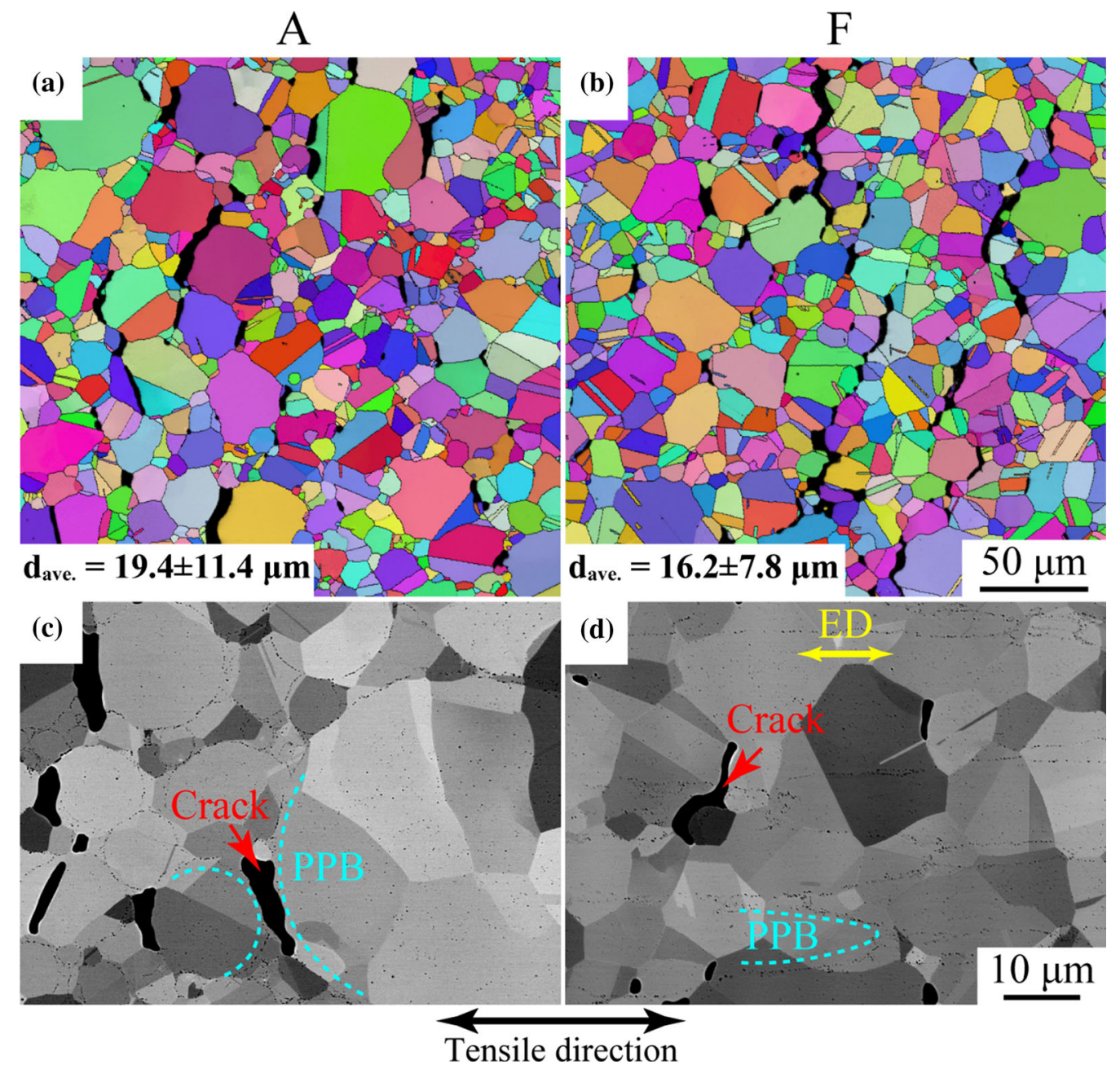

Fig. 7-Typical fracture characteristics at high temperature $\left(1180^{\circ} \mathrm{C}\right)$ and strain rate of $0.001 \mathrm{~s}^{-1}$ for the samples A and F. $(a)$, $(b)$ EBSD IQ + IPF maps and $(c),(d)$ SEM-BSE images of cross sections near fracture tips. Tensile direction is horizontal.

possibly formed by the coalescence of nucleated fine cavities.

\section{DISCUSSION}

\section{A. Effects of Various Microstructural Factors on Hot Workability}

Based on the results, it was found that the deformation at an intermediate temperature ( $\gamma^{\prime}$ sub-solvus) and low strain rate is optimal for the hot working. This is because these conditions are needed for superplastic deformation to occur. In addition to the effects of the deformation conditions, initial microstructure also had a significant effect on the hot workability at the peak temperature of $\sim 1100{ }^{\circ} \mathrm{C}$ (Figure 5(a)), indicating that it is also important to control the initial microstructure. Various microstructural effects on the hot workability are discussed below.

The effect of $\gamma^{\prime}$ precipitates on the hot workability was evaluated through similar high-temperature tensile tests using a $C \& W$ alloy $720{ }^{[19]}$ In that study, a sample with coarse cooling $\gamma^{\prime}$ precipitates showed better hot workability at $\sim 1040{ }^{\circ} \mathrm{C}$ than that of a sample with fine cooling $\gamma^{\prime}$ precipitates. However, at $\sim 1065^{\circ} \mathrm{C}$, the hot workability of the latter sample increased sharply, and the effect of the morphology of the $\gamma^{\prime}$ precipitates became negligible. This result indicates that the effect of the initial $\gamma^{\prime}$ precipitate becomes negligible above a certain temperature in the case of similar grain microstructures. This suggests that initial grain size, rather than $\gamma^{\prime}$ precipitates, is considered to be primary factor which determines the hot workability at the optimal temperature range $\left(1050{ }^{\circ} \mathrm{C}\right.$ and $\left.1100{ }^{\circ} \mathrm{C}\right)$. This is reasonable because $\gamma^{\prime}$ volume fraction and its strength decrease with approaching the $\gamma^{\prime}$ solvus temperature.

A fine-grained microstructure is necessary for ensuring high hot workability. For example, samples D and E with the average grain sizes of $\sim 20 \mu \mathrm{m}$ showed RA values lower than 25 pct even at the optimal deformation temperature and the lowest strain rate. It can be found that the coarse-grained microstructures prevent superplastic deformation and instead result in intergranular fracture and low hot workability, regardless of the deformation conditions. Therefore, a sub-solvus HIP temperature (i.e., samples A, B) is preferable 


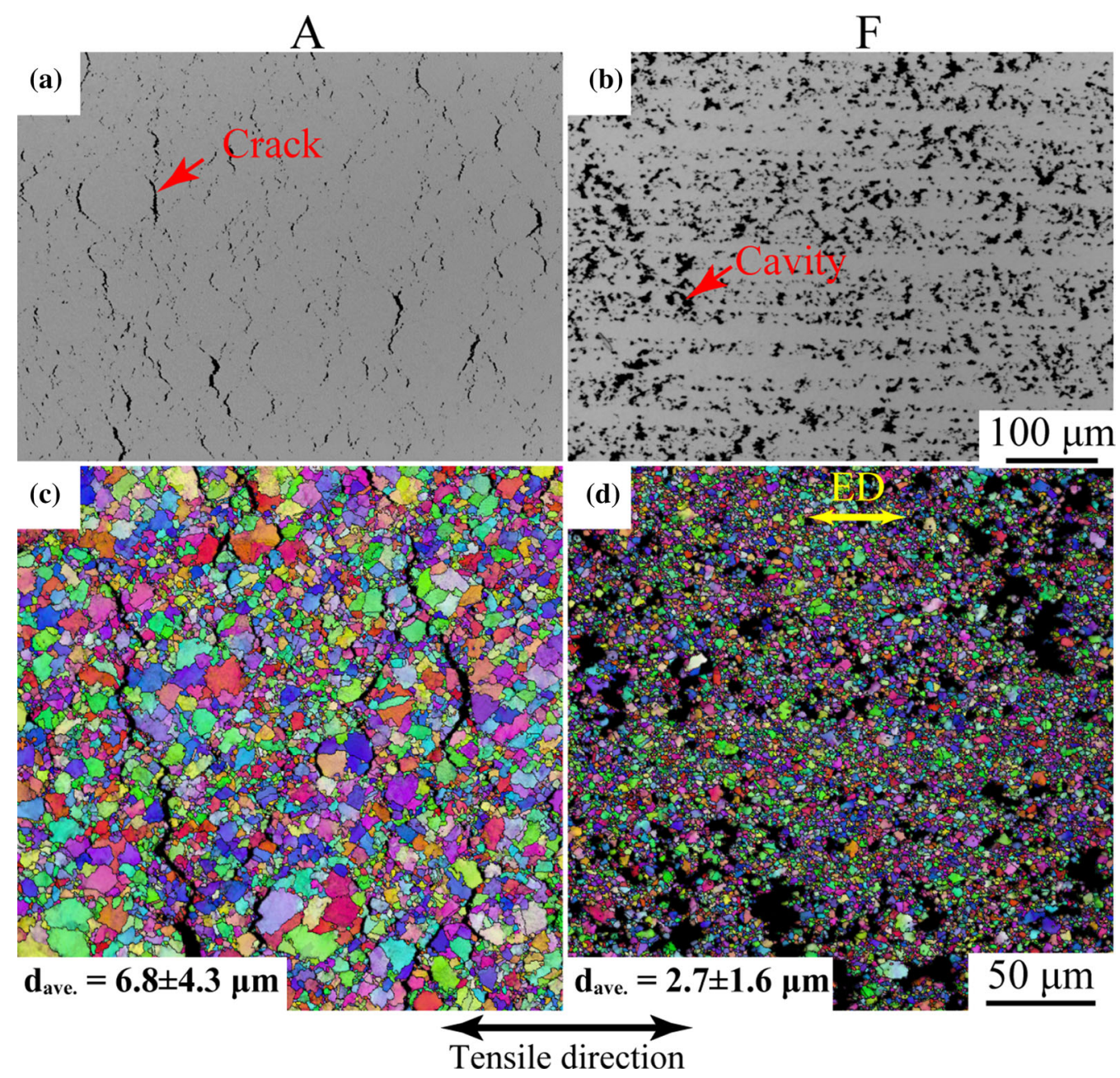

Fig. 8-Typical fracture characteristics at low temperature $\left(950^{\circ} \mathrm{C}\right)$ and strain rate of $0.001 \mathrm{~s}^{-1}$ for the samples $\mathrm{A}$ and $\mathrm{F}$. (a), (b) OM images and $(c),(d)$ EBSD IQ + IPF maps of cross sections near fracture tips.

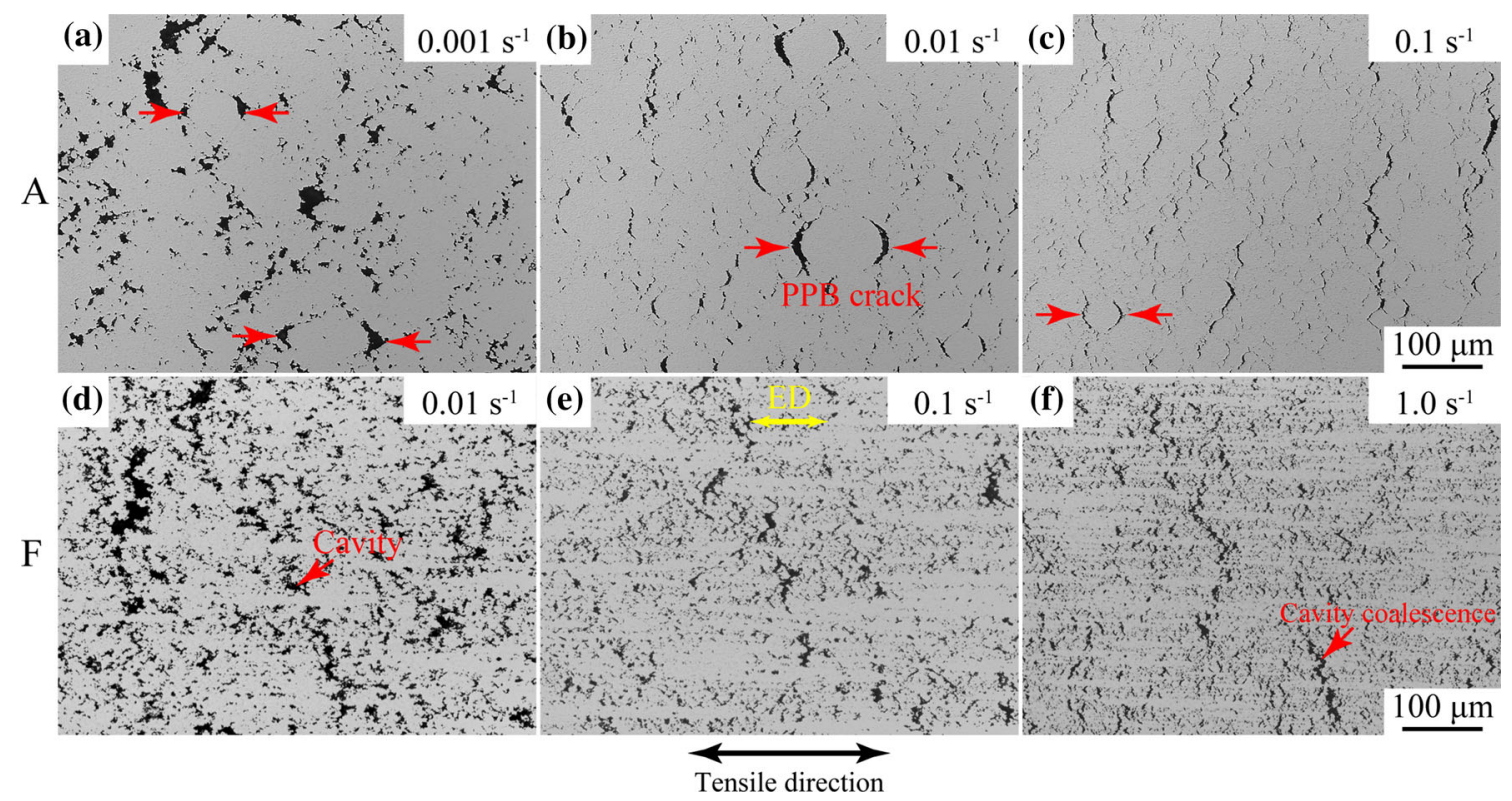

Fig. 9-Typical fracture characteristics at $1050{ }^{\circ} \mathrm{C}$ and different strain rates from $0.001-0.1 \mathrm{~s}^{-1}$ for $(a)$ to $(c)$ sample A and from 0.01 to $1.0 \mathrm{~s}{ }^{-1}$ for $(d)$ to $(f)$ sample F. Typical cavities or cracks along PPBs are indicated by red arrows. 
because fine-grained microstructures with an average grain size of less than $7.0 \mu \mathrm{m}$ can be obtained. Furthermore, it should be noted that there was significant difference approximately 25 pct in hot workability between sample $\mathrm{A}$ and sample $\mathrm{C}$ although the average grain size difference was only $1.4 \mu \mathrm{m}$, which indicates that hot workability is so sensitive to grain size. In this way, the smaller the initial grain size, the better to obtain superior hot workability. Grain size control during powder consolidation by HIP is very important for subsequent hot extrusion and isothermal forging.

All samples were fabricated using the powder with the same particle size range $(<106 \mu \mathrm{m})$. Therefore, PPB densities of those samples should be the same. PPBs have a detrimental effect on the hot workability, as they act as cavity nucleation sites and crack paths and affect adversely especially in the lower temperatures and higher strain rates (Figures 8 and 9). Fine-grained microstructure accelerates the DRX occurrence (Figure 3) and its fracture is less likely to occur along the PPBs, which lead to the superior hot workability when the optimal deformation temperature and low strain rate are selected. Still, PPB fracture clearly occurs and decreases the hot workability when the strain rate is increased even at the optimal temperature in the case of the as-HIP sample (Figures 9(b) and (c)). The presence of PPBs narrows the processing window in terms of both the temperature and the strain rate to a greater or less degree. In order to expand the processing window of the as-HIP samples, the as-HIP sample should be followed by hot extrusion not only to obtain fine microstructures but also to disperse the PPB precipitates within grains, as the conventional processing route of $\mathrm{P} / \mathrm{M}$ superalloys. ${ }^{[16,17]}$

\section{B. Cavity Nucleation Behavior and Its Control for Ensuring High Hot Workability}

Whether the tensile specimen shows superplastic deformation (excellent hot workability) under the optimal deformation conditions depends on the fracture characteristics. Superplastic deformation is often accompanied by the formation of cavities aligned along the tensile direction near the fracture tip (Figures 8(b) and 9(d) through (f)). These cavity distributions are called for "cavity stringers."[24] The cavities are connected with each other and increase in size, resulting in intergranular fracture. In this study, the extruded sample F showed large elongations, especially at 1050 ${ }^{\circ} \mathrm{C}$ and $1100{ }^{\circ} \mathrm{C}$, and cavity stringers were frequently observed at the cross sections of the fracture tips. In contrast, any cavity stringer was not observed in the as-HIP sample even though they contained a large number of cavities (Figures 8 and 9). This is because those samples were fractured by early PPB crack propagation before the cavity stringers could develop. Although the facture characteristics of the as-HIP and extruded samples were apparently different (Figures 7, 8 and 9), the underlying fracture mechanism should be cavity nucleation in both samples. Therefore, it is important to control cavity formation to ensure high hot workability. Herein, we discuss the cavity nucleation mechanism using the extruded sample, which showed superplastic deformation. Figure 10 shows the EBSD IQ + IPF maps and the corresponding KAM maps of the extruded sample deformed at $1050{ }^{\circ} \mathrm{C}$ for different strain rates (from 0.01 to $1.0 \mathrm{~s}^{-1}$ ). At a low strain rate $(0.01$ $\mathrm{s}^{-1}$ ), the microstructure consisted of fine and equiaxed grains with similar sizes, and the density of the sub-grain boundaries was low (Figures 10(a) and (d)). This indicates that deformation speed and DRX is well balanced. However, with the increase in the strain rate, the microstructure became inhomogeneous and consisted of both fine and coarse grains. Moreover, the density of the sub-grain boundaries was significantly higher compared with that for a low strain rate, indicating that DRX does not follow the deformation speed (Figures 10(b), (c), (e), and (f)). This resulted in the formation of un-recrystallized grains with high KAM values, and most of the cavities were found at the top and bottom of the coarse un-recrystallized grains along the tensile direction. Thus, cavity nucleation during the superplastic deformation of the extruded sample is closely related to DRX instability. In addition, the reason for the high density of fine cavities at $950{ }^{\circ} \mathrm{C}$ (Figure 8(b)) is that the deformation temperature is too low for DRX to occur sufficiently, because DRX is a thermally activated process. Thus, the effects of the strain rate and temperature on the cavity formation behavior during superplastic deformation are consistent with those observed in a Ti alloy. ${ }^{[26]}$ It was found that the acceleration of the DRX process is necessary for superplastic deformation. For the purpose, it is necessary to select the optimal deformation conditions and prepare the optimal initial microstructure. A finegrained microstructure accelerates the DRX, as it means that a large number of DRX nucleation sites (grain boundaries) are present, in contrast to the case for a coarse one. In contrast, the DRX process is retarded in the case of a coarse microstructure, which results in the formation of a large number of cavities owing to the instability of the DRX process.

\section{CONCLUSIONS}

In this study, the effects of the deformation condition and initial microstructure on the hot workability were investigated in detail using a conventional $\mathrm{P} / \mathrm{M}$ disk superalloy. The primary results of the study can be summarized as follows:

1. A fine microstructure with an average grain size of less than $7 \mu \mathrm{m}$ could be achieved by selecting sub-solvus temperature HIP conditions. A higher HIP temperature above $\gamma^{\prime}$ solvus $\left(1170{ }^{\circ} \mathrm{C}\right)$ and longer holding time ( 24 hours) resulted in the grain coarsening. In contrast, there was little effect of the HIP pressure on the grain size. Spherical PPB networks decorated by dark PPB precipitates were observed regardless of the HIP conditions. The microstructure was significantly refined by hot extrusion, and the average grain size became 3.7 $\mu \mathrm{m}$. The spherical PPB precipitate networks were 


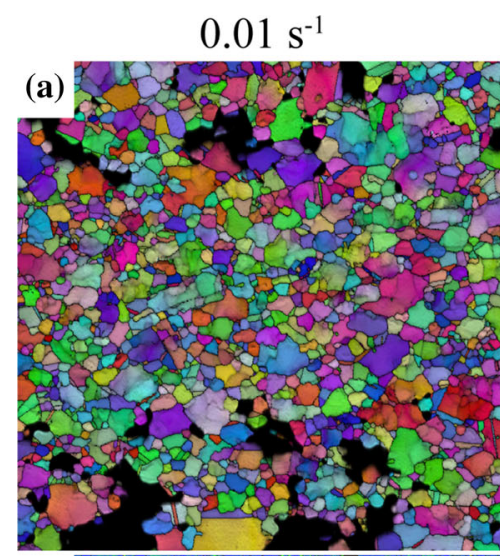

\section{(d)}

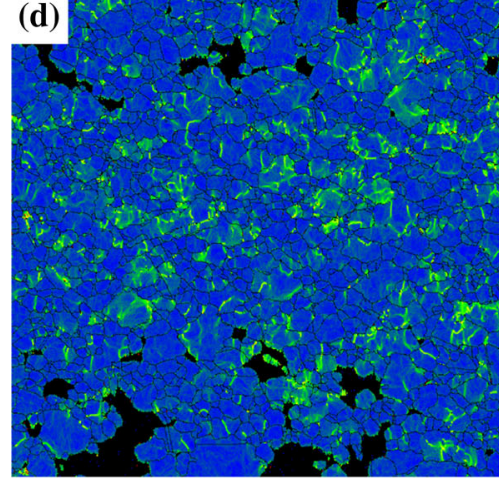

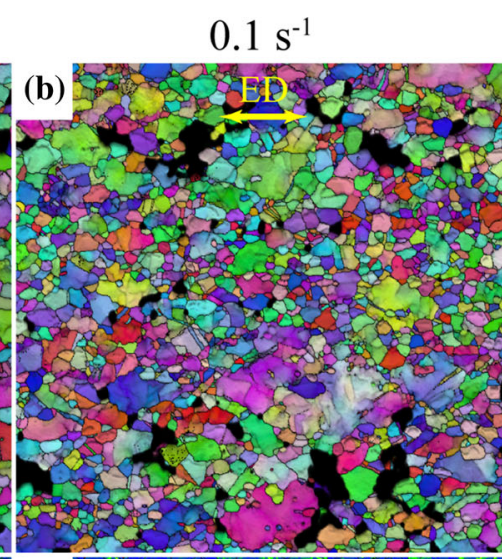

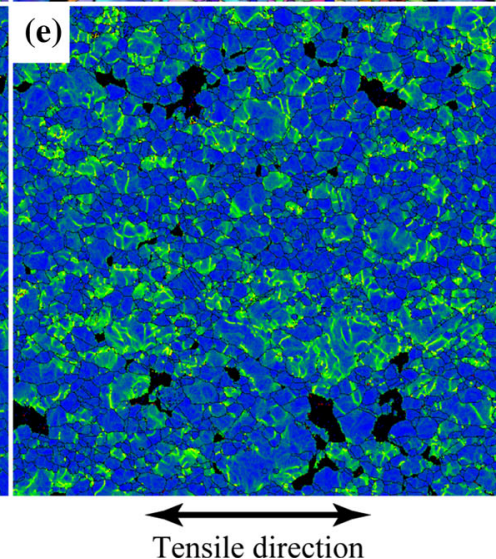

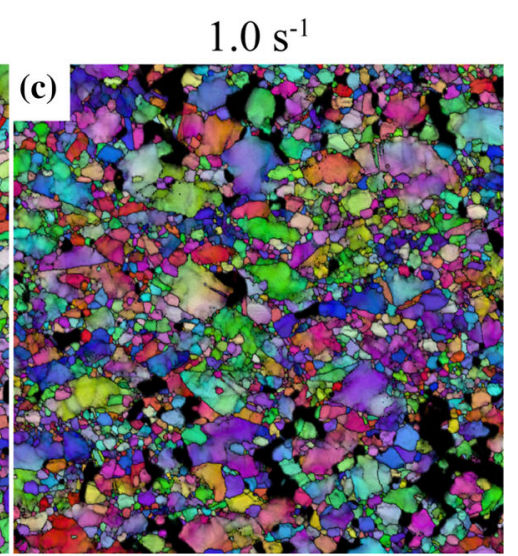

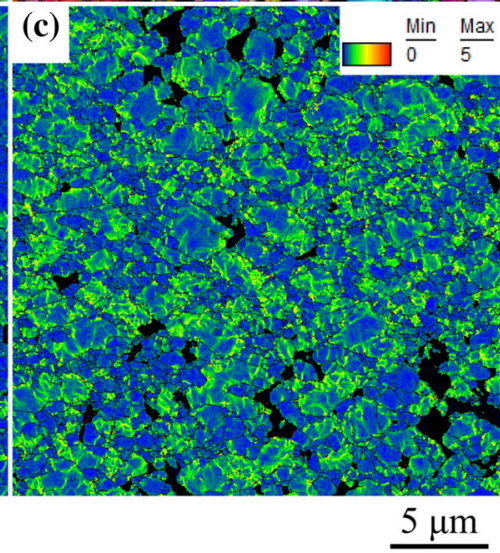

Fig. 10-EBSD IQ + IPF maps and corresponding KAM maps near fracture tips of sample $\mathrm{F}$ deformed at $1050{ }^{\circ} \mathrm{C}$ and different strain rates showing cavity formation and DRX behavior. $(a)$ and $(d) 0.01 \mathrm{~s}^{-1},(b)$ and $(e) 0.1 \mathrm{~s}^{-1}$, and $(c)$ and $(f) 1.0 \mathrm{~s}^{-1}$.

heavily distorted along the extrusion direction, and the precipitates were no longer at the grain boundaries but within grains.

2. The hot workability was found to be sensitive to both the deformation condition and initial microstructure. The hot workability monotonically increased with a decrease in the grain size at the $\gamma^{\prime}$ sub-solvus temperature. However, at temperatures higher and lower than this temperature, there was no significant effect of the initial microstructure except for the extruded sample F. With respect to the strain rate dependence at the peak temperature of $1050{ }^{\circ} \mathrm{C}$, the RA value of the sample with a fine microstructure (sample A) decreased with an increase in the strain rate at $1050{ }^{\circ} \mathrm{C}$. However, the sample with a coarse microstructure (sample D) did not show any effect of the strain rate, exhibiting low RA values regardless of the strain rate.

3. The PPBs became cavity nucleation sites and crack paths in the case of the HIP samples, especially at the lower temperatures and higher strain rates. This obviously resulted in a decrease in the hot workability. In contrast, the extruded sample did not undergo PPB fracture and exhibited high RA values even at the higher strain rates and lower temperatures. Thus, the processing window can be widened significantly by hot extrusion.
4. For superplastic deformation to occur, it is necessary to reduce the probability of cavity nucleation and coalescence. The former can be achieved by preparing a fine microstructure and selecting the optimal deformation conditions, such that the DRX can keep up with the deformation speed. The latter can be achieved through hot extrusion.

\section{ACKNOWLEDGMENTS}

This work was supported by Innovative Science and Technology Initiative for Security Grant Number JPJ004596, ATLA, Japan.

\section{OPEN ACCESS}

This article is licensed under a Creative Commons Attribution 4.0 International License, which permits use, sharing, adaptation, distribution and reproduction in any medium or format, as long as you give appropriate credit to the original author(s) and the source, provide a link to the Creative Commons licence, and indicate if changes were made. The images or other third party material in this article are included in the 
article's Creative Commons licence, unless indicated otherwise in a credit line to the material. If material is not included in the article's Creative Commons licence and your intended use is not permitted by statutory regulation or exceeds the permitted use, you will need to obtain permission directly from the copyright holder. To view a copy of this licence, visit http://creat ivecommons.org/licenses/by/4.0/.

\section{REFERENCES}

1. F.E. Sczerzenie and G.E. Maurer: Proceedings of the 5th International Symposium on Superalloys, 1984, pp. 573-80.

2. Y.F. Gu, C. Cui, H. Harada, T. Fukuda, D. Ping, A. Mitsuhashi, K. Kato, T. Kobayashi, and J. Fujioka: Proceedings of the 11th International Symposium on Superalloys, 2008, pp. 53-61.

3. Y. Mori, K. Kawagishi, T. Osada, H. Harada, M. Yuyama, Y. Takata, M. Osawa, and A. Ikeda: Metall. Mater. Trans. A, 2020, vol. 51A, pp. 2035-43.

4. K.A. Green, J.A. Lemsky, and R.M. Gasior: Proceedings of the 8th International Symposium on Superalloys, 1996, pp. 697-703.

5. Q.Y. Yu, Z.H. Yao, and J.X. Dong: Mater. Char., 2015, vol. 107, pp. 398-410.

6. F. Liu, J. Chen, J. Dong, M. Zhang, and Z. Yao: Mater. Sci. Eng. $A$, 2016, vol. 651 , pp. $102-15$.

7. A. Nicolaÿ, G. Fiorucci, J.M. Franchet, J. Cormier, and N. Bozzolo: Acta Mater., 2019, vol. 174, pp. 406-17.

8. S.L. Semiatin, K.E. MacClary, A.D. Rollett, C.G. Roberts, E.J. Payton, F. Zhang, and T.P. Gabb: Metall. Mater. Trans. A, 2013, vol. 44A, pp. 2778-98.

9. T.G. Langdon: J. Mater. Sci., 2009, vol. 44, pp. 5998-6010.

10. G.A. Rao, M. Srinivas, and D.S. Sarma: Mater. Sci. Eng. A, 2006 , vols. 435-436, pp. 84-89.
11. L. Chang, W. Sun, Y. Cui, and R. Yang: Mater. Sci. Eng. A, 2014, vol. 599, pp. 186-95.

12. C.L. Qiu, M.M. Attallah, X.H. Wu, and P. Andrews: Mater. Sci. Eng. A, 2013, vol. 564, pp. 176-85.

13. L.N. Moskowitz, R.M. Pelloux, and N.J. Grant: Proceedings of the 2nd International Symposium on Superalloys, 1972, pp. 1-25.

14. X. Pierron, A. Banik, G. E. Maurer J. Lemsky, D. U. Furrer, and S. Jain: Proceedings of the 9th International Symposium on Superalloys, 2000, pp. 425-33.

15. G.E. Maurer, W. Castledine, F.A. Schweizer, and S. Mancuso: Proceedings of the 8th International Symposium on Superalloys, 1996, pp. 645-52.

16. L. Tan, Y. Li, C. Liu, C. Yang, H. Ding, L. Huang, F. Liu, Z. Qin, and L. Jiang: Mater. Char., 2018, vol. 140, pp. 30-38.

17. Q. Bai, J. Lin, G. Tian, J. Zou, and T.A. Dean: J. Powder Metall. Min., 2015, vol. 4, p. 1000127.

18. M. Higashi and N. Kanno: Mater. Des., 2020, vol. 194, p. 108926.

19. M. Fahrmann and A. Suzuki: Proceedings of the 11th International Symposium on Superalloys, 2008, pp. 311-16.

20. R.W. Armstrong: Mater. Trans., 2014, vol. 55, pp. 2-12.

21. A. Belyakov, H. Miura, and T. Sakai: Scr. Mater., 2000, vol. 43, pp. $21-26$

22. S.L. Semiatin, K.E. McClary, A.D. Rollett, C.G. Roberts, E.J. Payton, F. Zhang, and T.P. Gabb: Metall. Mater. Trans. A, 2012, vol. 43A, pp. 1649-61.

23. T.P. Gabb, J. Gayda, and J. Falsey: NASA/TM-2005-213649, 2005

24. A. Yousefiani, J.C. Earthman, and F.A. Mohamed: Acta Mater., 1998, vol. 46, pp. 3557-70.

25. S.R. Reddy, S. Bapari, P.P. Bhattacharjee, and A.H. Chokshi: Mater. Res. Lett., 2017, vol. 5, pp. 408-14.

26. E. Alabort, D. Putman, and R.C. Reed: Acta Mater., 2015, vol. 95 , pp. $428-42$.

Publisher's Note Springer Nature remains neutral with regard to jurisdictional claims in published maps and institutional affiliations. 